\title{
LA PARADOJA PARTIDISTA: INSTITUCIONALIZACIÓN Y REPRESENTACIÓN EN LOS PARTIDOS POLÍTICOS LATINOAMERICANOS
}

\author{
Esther del Campo* y $\mathrm{M}^{\mathrm{a}}$ Luisa Ramos**
}

\section{INTRODUCCIÓN}

El análisis de los partidos políticos y de los sistemas de partidos constituye uno de los ámbitos más fecundos en el marco de la política comparada: si repasaramos aunque brevemente la literatura en torno a éstos, nos encontraríamos con estudios sobre las relaciones entre partidos y electores en términos de estabilidad y cambio de las preferencias electorales; o desde una perspectiva más sociológica de análisis del apoyo partidista; sobre la importancia de los partidos en el gobierno y la formación de coaliciones; o sobre partidos y formación de políticas. Más recientemente, también se han llevado a cabo investigaciones en torno a los partidos políticos como actores estratégicos en las campañas electorales. En general, puede afirmarse como señala Mair para el estudio de las organizaciones partidis$\operatorname{tas}^{1}$, que a consecuencia de la influencia de los partidos de masas, todavía hoy existe una tendencia a evaluar estas organizaciones en términos de sus relaciones con la sociedad civil. De este modo, se han descuidado aspectos relacionados con el partido en el parlamento o el partido en el gobierno. En este sentido, parece abrirse un gran abanico de perspectivas novedosas frente al tradicional estudio de las relaciones que establecen los partidos con sus bases sociales o con la sociedad civil en su conjunto.

Sin embargo, a nuestro entender esta relación no termina de estar zanjada, así, el presente análisis va a intentar replantear la relación entre los partidos, la sociedad civil y el Estado en los contextos de consolidación democrática en América Latina, insistiendo fundamentalmente en los aspectos de la representatividad partidista y cómo es percibida por la clase política. Consideramos que la visión de ésta influye de modo determinante en la conformación, interpretación y diseño de la propia relación del partido con la sociedad y de la propia centralidad de los partidos en el sistema político.

Si históricamente el desarrollo de los partidos vino ligado al proceso de lucha por la extensión del sufragio, de las prerrogativas parlamentarias y la aparición de los parti- dos de masas, señala Lenk: "la aparición de los partidos en un Estado supone, por sí sola una ruptura con el pasado, porque los partidos, en cuanto incorporación espontánea y no institucionalizada de ideas e intereses sociales, implican que la sociedad se levante contra el Estado para alterar la estructura de dominación ... La sociedad civil y sus representantes de las capas hegemónicas sólo pueden imponerse apoderándose del Estado y en esta labor sólo los partidos políticos son instrumentos adecuados para una reforma del Estado en el sentido de su 'socialización'" 2

Este proceso que se inicia desde mediados del siglo XIX, y culmina en las primeras décadas del siglo XX, fortalece a los partidos políticos en el ámbito estatal, actuando éstos como mediadores entre el Estado y la sociedad civil y, llevando a la construcción de lo que se ha llamado el "Estado de partidos", en la famosa expresión de Triepel, adaptada a nuestro ámbito por García Pelayo ${ }^{3}$. Se manifiesta así, la profunda ambivalencia de los partidos políticos, expresando por un lado, la autonomía de la voluntad de los ciudadanos, mientras que por otro, insertan por sí esa voluntad en los órganos del Estado.

La etapa siguiente, conformada por el paso del partido de masas a lo que se ha llamado, "partido atrapalotodo" o "partido escoba"(Kirchheimerx), o en palabras de Panebianco "partido electoral-profesional" ${ }^{5}$, ha significado una erosión del vínculo partido-sociedad civil, y un fortalecimiento de la relación entre partido y Estado, especialmen-

* Universidad Complutense de Madrid.

** Universidad Pública de Navarra.

1. P. Mair (1994): "Party Organizations: From Civil Society to the State” en Richard S. Katz y P. Mair (Eds.): How Parties Organize, Sage, London, pág. 3.

2. K. Lenk y F. Neumann (1980): Teoría y Sociología críticas de los partidos políticos, Anagrama, Barcelona.

3. M. García-Pelayo (1986): El Estado de partidos, Alianza Ed., Madrid.

4. O. Kirchheimer (1966): “The Transformation of West European Party Systems”, en J. LaPalombara y M. Weiner (Eds.), Political Parties and Political Development, Princeton Univ. Press, Princeton, pp. 177-200.

5. A. Panebianco (1988): Political Parties: Organization and Power, Cambridge Univ. Press, Cambridge. 
te desde la perspectiva de obtención de recursos del partido (algunos autores, como Katz y Mair dan un paso más, y señalan que los partidos políticos se han convertido en brokers independientes entre el Estado y la sociedad civil) ${ }^{6}$.

Partiendo del reconocimiento de que la democracia parlamentaria tal y como es concebida en nuestros días no puede funcionar sin partidos políticos, existe el peligro de la partidización del Estado, que no implica necesariamente ni un reforzamiento de la autoridad estatal, ni un acercamiento obligado a la sociedad civil. Es decir, si sólo prevalece la idea de la democracia como "método político", en el fondo, estaremos equiparando electores con ciudadanos y pensaremos que sólo en la arena electoral, y previa mediación del partido político, es cuando se produce ese proceso de integración de la sociedad en el Estado. Sin embargo, en otra lógica, el funcionamiento de la democracia debe precisar del ejercicio de la participación política, que no sólo significa participación electoral (aquí mencionar el elevado nivel de abstencionismo que se produce en numerosos países de América Latina, o incluso el abstencionismo creciente, en otros países donde el voto es obligatorio) sino el desarrollo de otras instancias de intermediación con el Estado $^{7}$ (en muchos de los países latinoamericanos, el intento de crear o mantener estas estructuras neocorportistas ha sido frenado por los tradicionales intereses corporativistas-populistas o neopopulistas).

Esta evolución partidista ha hecho que la desafección política se convierta en un hecho recurrente, también en América Latina, es decir, el individuo deviene apolítico, y la actitud ante el Estado de quien recibe un servicio, no es precisamente participación política, sino una genérica actitud reivindicativa, que espera asistencias sin querer imponer decisiones ${ }^{8}$.

Por un lado, en América Latina parece haberse consolidado la vinculación-inserción de los partidos en el Estado y su consiguiente fortalecimiento, pero por otro, los partidos parecen haberse desvinculado de la sociedad (en algunos casos nacionales, esta vinculación no llegó a producirse), y esta vinculación sólo se logra en momentos puntuales, de retorno a la democracia, explosión democrática en contra de la corrupción o surgimiento de movilizaciones de corte populista-reformista o propuestas antipolíticas ${ }^{9}$. En este sentido, la paradoja se concreta en que no podemos hablar de un declive del partido per se, "sino que los partidos son ahora cada vez más fuertes” —están más institucionalizados-, "pero son también más remotos; tienen más control, pero son también menos poderosos; y son al tiempo más privilegiados, pero también menos legítimos" ${ }^{10}$.

Por otro lado, la "estatalización" de la representación política significa en América Latina, problemas añadidos. Es decir, obliga a replantearnos la relación entre la sociedad civil y el Estado, y "la representación de lo social". Como señala Lechner ": "En la mayoría de los países latinoamericanos el Estado no representa lo que Marx denominara la síntesis de la sociedad civil. Nuestras sociedades tienen demasiadas desigualdades económicas, distinciones sociales, divisiones étnicas, para que adquiera arraigo cul- tural la forma Estado como una abstracción que resuma y exprese la vida social. No sólo son débiles los mecanismos de integración cultural, también son insuficientes las redes de integración estructural, tanto por parte de la sociedad (mercado) como del mismo Estado (burocracia)". Si los partidos se desvinculan de la sociedad, si confundimos el Estado con los gobiernos, si se acrecienta la "enfermedad de la representación" ${ }^{12}$, nos encontramos con los nuevos retos planteados a las democracias latinoamericanas.

6. R.S. Katz y P. Mair (1992): "Introduction: The Cross-National Study of Party Organizations", en R.S. Katz y P. Mair (Eds.): Party Organizations: A Data Handbook on Party Organizations in Western Democracies, 1960-90, Sage, London.

7. Véase a C. Offe (Partidos políticos y nuevos movimientos sociales, Ed. Sistema, Madrid, 1988) o a A. Wolfe (El derrumbe de los mecanismos de mediación), cuando señalan el peligro que tiene la democracia de partidos frente al surgimiento de los nuevos movimientos sociales y las tendencias neocorporatistas de mediación de intereses, que vendrían a socavar la base territorial de la representación. También otros autores han subrayado que los partidos han cambiado y están bajo amenaza (R.J Dalton, S.C. Flanagan y P.A. Beck (Eds.)(1984): Electoral Change in Advanced Industrial Democracies: Realignment or Dealignment?, Princeton Univ. Press, Princeton) o que han fracasado en sus funciones tradicionales de representación (K. Lawson y P. Merkl (Eds.)(1988) When Parties Fail: Emerging Alternative Organizations, Princeton Univ. Press, Princeton).

8. Esta insuficiencia de la participación no resulta sólo de la perspectiva que adopta el ciudadano frente a la "política enajenada" (en palabras de Wolfe) sino que también es consecuencia de la institucionalidad política, y no se produce sólo en contextos de países menos desarrollados, sino que es también una característica de sistemas políticos más avanzados. Así, Russell Dalton indica que "dado que el proceso político en la mayoría de las democracias presume un público pasivo y deferente, existen insuficientes oportunidades de los ciudadanos para incrementar su participación en el proceso de decisiones políticas. Especialmente, en Europa Occidental, las instituciones democráticas fueron diseñadas para limitar y canalizar la participación ciudadana, no para maximizar el control popular de las élites. R. J. Dalton (1988): Citizen Politics in Western Democracies, Chatham House Publ., N. J.: Chatham, pág. 226.

Como ejemplo podemos reseñar los estudios sobre actitudes ante los partidos políticos llevadas a cabo en el Sur de Europa, que indican que "las actitudes populares en el Sur de Europa hacia los partidos políticos son muy ambivalentes, si no contradictorias. Los ciudadanos mantienen simultáneamente algunas actitudes bastante positivas (particularmente en lo que se refiere a las funciones básicas de los partidos en los sistemas democráticos) y otras que son decididamente negativas". Véase $\mathrm{R}$ Gunther, J. R. Montero y M. Torcal (1994): Anty Party Sentiments in Southern Europe: A Preliminary Exploration, Conference on Political Parties: Changing Roles in Contemporary Democracies, Centro de Estudios Avanzados en Ciencias Sociales, Instituto Juan March, 15-17 de diciembre, pág. 7.

En América Latina, resulta interesante rescatar la paradoja que señalan C. Perelli y D. Zovatto, al contrastar la generalizada valoración de la democracia como "posibilidad de ejercer la libertad individual y de hacer respetar los derechos humanos de los habitantes" con las duras críticas que reciben los gobiernos, los Parlamentos, las organizaciones partidistas y la clase política en general. Véase C. Perelli y D. Zovatto (1994): "Introducción: partidos y liderazgos y consolidación democrática en América Latina" en C. Perelli, S. Picado y D. Zovatto (Comps.) (1994), Partidos y clase política en América Latina en los 90, IIDH-CAPEL, San José de Costa Rica, pág. XVI.

9. En este sentido, habría que verificar como señala Wolfe, en "E derrumbe de los mecanismos de mediación”, el surgimiento de partidos apolíticos, cuyos principios más fundamentales incluyen la prevención de la politización en la mayor medida posible. Esta "desparticipación" o "deslegitimación" de los partidos, los convierte entonces, no en vehículos de expresión de los conflictos, sino en partes del conflicto mismo.

10. P. Mair, ob. cit, pág. 19.

11. N. Lechner (1992): "La política ¿debe y puede representar a lo social?", en Mario R. dos Santos (Coord.), ¿Qué queda de la representación política?, Ed. Nueva Sociedad, Caracas, pág. 136.

12. Como señala Bernard Manin, hemos asistido a un tránsito desde la democracia de partidos a la democracia de lo público, que ha traído 
Frente al modelo europeo, conviene insistir en la debilidad relativa de los partidos políticos latinoamericanos ante el Estado, y en su escasa relevancia en contextos políticos marcados por el caudillismo y el caciquismo ${ }^{13}$. Así, mientras que en el caso europeo, los partidos políticos respondieron a la matriz clásica de formación como prolongación del conflicto en el ámbito social entre las distintas clases sociales; en América Latina, la acción partidista fue más la expresión de coaliciones policlasistas que actuaron en nombre del pueblo y de la nación. De este modo, la primacía de lo político estatal significó como señala Touraine la primacía de la autoidentificación política de los sujetos sociales por sobre su identificación social ${ }^{14}$. Y retoma -explicando el sistema partidista brasileño y mexicano, aunque es posible generalizar- en un texto ya clásico Liliana de Riz: "El doble patrón de ciudadanía regulada por el Estado y creación estatal de partidos hace que la noción de 'partido' en ese contexto recubra una realidad muy diferente de la de las otras sociedades: los partidos como instrumentos de la integración nacional antes que como mecanismos de la democracia política, mecanismos del Estado antes que de la sociedad" ${ }^{15}$.

\section{TRANSICIÓN Y CONSOLIDACIÓN DEMOCRÁTICA}

\section{II.1. Los nuevos desafíos a los partidos políticos latinoamericanos}

El "reencauzamiento democrático" que se produce en la mayoría de los países latinoamericanos a comienzos de los años ochenta, va a redimensionar el papel de los partidos políticos, que se van a convertir en los principales actores del nuevo contexto político. Así, y hecho probado para todos los analistas de los procesos de transición, la tarea de creación y organización de los partidos debe tener una especial prioridad en la agenda de los líderes democráticos en el período de transición ${ }^{16}$. Los partidos han de ser las instituciones encargadas de canalizar los intereses, pero también las renovadas energías, de los movimientos sociales, sindicatos de trabajadores y otras organizaciones antiautoritarias presentes en el comienzo de la reemergencia de la sociedad civil. Sin partidos sería muy difícil negociar los compromisos necesarios entre los principales actores políticos y neutralizar las explicables pero peligrosas tendencias manejadas por los "maximalistas" que pueden minar la transición a una democracia estable.

Además, los partidos pueden crear, reciclar y airear símbolos de identidad política que salven muchos de los "gaps", los tradicionales y los no tanto, que dividen a la sociedad: clase, estatus, familia, género, religión, región, etnicidad, etc. Por otro lado, como señala O'Donnell: "La necesidad de poner juntos símbolos que atraigan suficientes votos y que aunen el umbral numérico para obtener representación tienden a restar énfasis a las distintas idiosincrasias que emergen durante la movilización antiautoritaria de la sociedad" ${ }^{17}$.
Pero este primer momento partidista es pronto superado por otro, donde de lo que se trata es de replantear el problema de la recomposición del sistema partidista, de sus conexiones internas y de sus relaciones con el resto de la sociedad. Este sería el proceso en el que se encontrarían los partidos políticos latinoamericanos; en muchos de los casos se ha asistido a una reformulación del espectro partidista con la aparición de terceras fuerzas políticas en sistemas tradicionalmente bipartidistas (como es el caso de Argentina y también en cierta medida de Uruguay), de partidos antipolíticos como es el caso peruano, o de personalismos neopopulistas (este hecho es bastante generalizable en todo el continente), o finalmente de síntomas de crisis partidista en sistemas políticos

históricamente bastante estables como es el caso de Colombia y Venezuela. Nos restaría un tercer momento, en el que se trataría de hacer coincidir la consolidación de la democracia con los necesarios impulsos de la democratización social.

\section{II.2. Partidos políticos y clase política en América Latina}

La fuente fundamental de información para la realización de este trabajo está constituída por las encuestas realizadas a la élite parlamentaria latinoamericana en el marco de la investigación "Élites parlamentarias en América Latina”, que se ha desarrollado en el Área de Ciencia Política de la Universidad de Salamanca dirigida por el profesor Manuel Alcántara. Utilizar a los diputados como fuente de información implica un reconocimiento de su importancia como parte de la élite decisional de sus respectivos países. En este caso, supone además un reconoci-

consigo importantes consecuencias para el entendimiento de la representación, como vínculo entre representante y representados: la elección de personalidades antes que de programas, el papel esencialmente reactivo del público, la elección sobre la base de imágenes relativamente vagas. $\mathrm{B}$. Manin (1992): “Metamorfosis de la representación”, en Mario R. dos Santos, ob. cit., pág. 39.

13. El personalismo de la política latinoamericana merecería de una atención más detallada por nuestra parte que no estamos en condiciones de abordar en este momento; sin duda, no se trata de un fenómeno arcaizante que pertenezca a la pre-política, sino que, como bien ha señalado Carlos Vilas al hablar de "los caudillos electorales de la posmodernidad", responde en la actualidad a las contradicciones existentes entre el principio democrático del gobierno de las mayorías y la concentración de las políticas gubernamentales en grupos minoritarios. Es decir, estamos hablando de la convivencia de la democracia con una creciente exclusión y marginalización social. Véase C. Vilas (1994): "Entre la democracia y el neoliberalismo: los caudillos electorales de la posmodernidad" en S. Dutrenit y L. Valdés (Coords.) (1994): El fin de siglo y los partidos politicos en América Latina, Ed. Instituto Mora/Universidad Autónoma Metropolitana, México, pp. 323-340.

14. A. Touraine (1978): Las sociedades dependientes: ensayos sobre América Latina, Siglo XXI, México.

15. L. de Riz (1986): "Política y partidos. Ejercicio de análisis comparado: Argentina, Chile, Brasil y Uruguay", en Desarrollo Económico, v. $25, n^{\circ} 100$, pág. 666.

16. Los más clásicos entre los clásicos, O’Donnell, G., P.C. Schmitter y L. Whitehead (Eds.) (1986): Transitions from Authoritarian Rule, Jokhns Hopkins Univ. Press, Baltimore.

17. G. O'Donnell, “Transitions to Democracy: Some Navigation Instruments", en R. A. Pastor (1989): Democracy in the Americas. Stopping the Pendulum, Holmes y Meier, New York, pág. 70. 
miento de su doble condición de diputados y miembros destacados de partidos, en tanto parte de una de las instituciones centrales del sistema político, el Parlamento, pero también miembros de la élite partidista. En este sentido, sus opiniones trascienden el hecho de ser una fuente primordial de información privilegiada, sino que las mismas tienen un impacto directo en diferentes procesos político ligados tanto a la consecución de niveles óptimos de gobernabilidad como, más importante para el caso que nos ocupa, una incidencia directa en la dinámica de su propio partido. Es en esta última faceta la que enfatizamos para la utilización de sus opiniones como fuente básica de información. El número total de casos o de encuestas utilizadas es de 883 , correspondiente a 13 países ${ }^{18}$. La unidad de análisis con la que trabajamos es el partido y, eventualmente, el sistema de partidos.

Para analizar hasta qué punto se está generando un nuevo modelo de partido, tanto en lo relativo a la relación de los mismos con la sociedad como en referencia al tipo de estructura partidista, se ha utilizado una serie de preguntas del cuestionario mencionado que consideramos que podrían medir de forma bastante precisa los interrogantes planteados previamente. Para el primer bloque, hemos indagado en la caracterización de la capacidad de los partidos para ejercer de forma eficiente dos de las funciones clásicas que la teoría asigna a los partidos políticos, la de intermediación y la de representación social. En este sentido, la existencia de factores tales como una progresiva distancia entre partidos políticos y sociedad, bajos niveles de militancia partidista, baja participación popular en los partidos o estructuras partidistas débiles y que funcionen sólo en momentos electorales, intervienen en la caracterización de un incumplimiento de esta función de representación de los partidos políticos y, por añadidura, de los Parlamentos. Para el segundo bloque, el que se refiere al tipo de estructura interna del partido, se han utilizado las siguientes variables: el grado de democracia interna, el tipo de estructura interna y la razón por la cual consideran que han sido elegidos. Partimos de la hipótesis de que la existencia de bajos niveles de participación ciudadana en los partidos, escasa democracia interna o la percepción de los diputados de haber sido elegidos por el arrastre del líder o el diseño de la campaña, en detrimento de cuestiones tales como la coincidencia del elector con el programa del partido, permite concluir que se está generando un modelo de partido claramente definible como institución decisional más que como institución representativa.

\section{II.3. Clase política, partidos y representación política}

La propia apreciación de los diputados latinoamericanos sobre estas cuestiones facilita un acercamiento apropiado a la caracterización del formato de representación que se está ejerciendo. En cuanto a la primera pregunta utilizada (cuadro 1 y gráfico 1 , recogidos en el anexo), que se refiere a la relación entre los partidos políticos y la sociedad, resulta significativo que la mayoría de los diputados latinoamericanos considere que existe un progresivo aleja- miento entre esta institución y los ciudadanos a los que representan. Resulta aún más indicativo que haya más diputados que perciban esta relación como marcada por una gran distancia que aquéllos que consideran que se mantienen fuertes vínculos entre los partidos y la sociedad. Los mayores porcentajes de diputados que señalan que existe una gran distancia entre los partidos y la sociedad se encuentran en el grupo de países formado por Perú, Brasil, Venezuela, Argentina y Colombia. Por debajo de la media en lo relativo a esta cuestión, señalando los porcentajes más altos de fuertes vínculos entre sociedad y partidos políticos, se sitúan los diputados de los países centroamericanos, más República Dominicana y Uruguay. En el primer grupo de países, esta percepción viene a coincidir con una manifiesta crisis de legitimidad de los partidos políticos existentes, producto, en algunos casos, de largas prácticas de gestión pública, como en Venezuela, Argentina o Colombia, o de ineficacia de la institución partidista, pese a intentos novedosos, para superar la crisis de representación, como en Perú o en Brasil. Resulta también significativo el caso chileno, sistema partidista tradicionalmente estable — pese al largo interregno militar- con fuertes subculturas partidistas, donde el $83 \%$ de los diputados señalan un progresivo alejamiento entre los partidos políticos y la sociedad civil.

En cuanto a la pregunta referida al nivel de militancia, de acuerdo a la apreciación de los diputados y tal como aparece en el cuadro 2, los diputados latinoamericanos consideran que los niveles de militancia partidista en sus respectivos países son bajos o muy bajos. Más del $50 \%$ de los diputados entrevistados así lo estiman en México, Venezuela, Perú, Uruguay y Brasil, destacando el mayor énfasis del caso de Brasil donde el índice alcanzaba a los dos tercios de los entrevistados. Estas diferencias en los índices de apreciación no pueden ser asociadas a las diferencias en los formatos de los sistemas de partidos o su caracterización como débiles o fuertes, ya que en aquellos países donde los diputados no se manifiestan tan insatisfechos con los niveles de militancia partidista son algunos de los casos más característicos de sistemas de partidos débiles como son los casos de Honduras, Rep. Dominicana, en los que, respectivamente, se considera el nivel de militancia muy alta o alto en un $72 \%$ y un $68 \%$.

Puede suponerse, por tanto, que la percepción de que los mayores niveles de militancia no van asociados a la mayor institucionalización de los sistemas de partidos, sino que pueden intervenir otros factores, como la misma diferencia en la percepción de cuáles son los niveles óptimos de militancia o la utilización de la vía partidista como forma de ascenso social, entre otros. Así mismo, dependería también de los diferentes tipos de partidos, más estructurados en torno a cuadros y organizaciones, más movimientistas; dependería también del contexto reciente y de cómo se haya producido la redemocratización ${ }^{19}$.

18. En el momento en que se realizó este trabajo estos eran los países de los cuales había datos disponibles.

19. Como señala P. Mair, el descenso en la membrecía de un partido no deja de ser relativo; los partidos políticos pueden ignorar hasta cierto punto las opiniones de sus miembros, pero los militantes continúan 
En esta misma línea, la apreciación de los diputados acerca de la participación popular en la vida partidista también arroja un panorama en el cual la mayoría de los diputados percibe que la participación se circunscribe a los momentos electorales, siendo esta impresión aún mayor en los países del Cono Sur y en Costa Rica (ver cuadro 3). Es decir, $\mathrm{y}$ a tenor de lo que indican los entrevistados, no es que la participación política sea escasa sino que únicamente se limita al momento de la cita electoral, percepción que está muy extendida entre los diputados de los diferentes países y que, salvo en Honduras, oscila entre el $52 \%$ de los diputados panameños que estiman que la participación política sólo se da en las elecciones y Brasil donde la cifra asciende al $75 \%$. Por el contrario, el único país latinoamericano en el que los diputados dicen percibir la participación popular en la vida de los partidos como intensa y constante es Honduras (57\%), muy lejos de la República Dominicana $(32 \%)$ que es el país que le sigue en el orden de conceder una mayor importancia a ese rubro. Evidentemente esta pregunta debe tener en cuenta el alto número de diputados que puedan estar refiriéndose a cuestiones muy distintas al señalar la intensa participación popular en los partidos políticos, expresión en la que sin duda pueden estar incluidas las prácticas clientelistas que pueden desarrollar los partidos. En todo caso, resulta de nuevo relativamente sorprendente el caso chileno, donde el $60 \%$ señala que la participación se produce sólo en elecciones y un $37 \%$, el porcentaje más elevado para esta respuesta, que indica que ésta es escasa y marginal.

El cuadro 4 muestra distintos grados de acuerdo con diversas afirmaciones referentes a la ideología partidista. Una primera, indaga el grado de acuerdo con la afirmación de que las diferencias ideológicas entre los partidos son cada vez menores. La inmensa mayoría de los diputados latinoamericanos perciben que no existen diferencias ideológicas entre partidos, oscilando entre el $28 \%$ de Venezuela y el $81 \%$ de Honduras. Costa Rica, El Salvador, Honduras y Colombia están por encima de la media en la visión de las escasas diferencias ideológicas entre los partidos políticos, mientras que México, Venezuela, Uruguay y Brasil apuestan más por un tipo de partido fuertemente ideologizado. Los mayores porcentajes de acuerdo con esta afirmación coinciden con los menores en lo que se refiere al grado de acuerdo con la existencia de una polarización extrema entre los partidos. De acuerdo a ello, los mayores porcentajes los presentan México y Venezuela, donde aún se percibe que existe un tipo de partido fuertemente ideologizado y que en esta línea, las diferencias ideológicas entre partidos son pronunciadas. Sin embargo, estas percepciones no significan que la clase política piense que la ideología es irrelevante, ya que solamente en el caso de Venezuela y de República Dominicana hay casi un $20 \%$ de diputados que están de acuerdo con esta premisa. En el resto de los países contemplados, los porcentajes de acuerdo son insignificantes. Con respecto a la afirmación de que la ideología es irrelevante, los niveles más altos de acuerdo se observan en Venezuela, Rep. Dominicana y Costa Rica, mientras que los menores se observan en Honduras, México, Colombia, Chile y Perú. Sin embargo, los niveles de acuerdo en este caso son mucho menores, así como la idea de que la ideología de los partidos de izquierda es más sólida que en los partidos de derecha.

Por último, en la figura 3, hemos reflejado las respuestas obtenidas al tipo de sistema de partidos que prefieren los diputados en estos países. La opción más repetida en todos los casos, con respuestas que superan el $50 \%$ de los entrevistados, es la que señala más de tres partidos. Esto significa que frente al bipartidismo mayoritario, en el cual el partido que gana las elecciones se lo lleva todo, pero que parece producir gobiernos estables, se han elegido sistemas multipartidistas, donde aumenta la representatividad de la sociedad, pero que pueden conducir más fácilmente a la parálisis gubernamental, fragmentación y polarización. A nuestro juicio, resultan especialmente significativos los casos de Argentina (sistema bipartidista desde 1945 hasta comienzos de los noventa, a pesar de la existencia de terceras fuerzas políticas), Colombia y Venezuela (sistemas bipartidistas estables) que están sufriendo una importante crisis. Resulta además interesante recordar que cuando se inicia la transición política, la discusión teórica en torno al sistema de partidos en muchos de estos países se centraba en las posibilidades reales que tenían los sistemas multipartidistas de encauzar estos procesos de transición, dado que Colombia y Venezuela, ambos países con sistemas bipartidistas, habían sido los más estables democráticamente ${ }^{20}$.

¿Hasta qué punto estas respuestas pueden ayudarnos a explicar el surgimiento de "nuevas formas de hacer política” en América Latina? Este fenómeno estaría relacionado con la crisis puesta de manifiesto en la función de representación de demandas por las estructuras partidistas, y en la aparición de los medios de comunicación en la arena política, asumiendo funciones de intermediación que previamente poseían los partidos políticos. En este contexto, resulta explicable el surgimiento de fuertes liderazgos y de "outsiders", candidatos que se postulan al margen de los partidos tradicionales, o incluso fuera de cualquier cauce partidista, arropados únicamente por la maquinaria electoral. En definitiva, lo que este fenómeno puede estar reflejando es una crisis importante en la legitimidad o credibilidad de los partidos políticos.

\section{II.3. La estructura interna de los partidos}

En cuanto al segundo bloque, el que se refiere al tipo de estructura interna del partido, se plantea la hipótesis de que un tipo de estructura fuerte, estable, con alta participación en la misma y amplia democracia interna genera un sistema de partidos fuerte y estable, siendo elementos que

siendo necesarios para obtener recursos, ocupar puestos y, sobre todo, para mantener la imagen de partido de masas. P. Mair (1994): "Party Organizations: From Civil Society to the State" en R.S. Katz y P. Mair, ob. cit., pp. 13-18.

20. Véase O. Hurtado (1989): "Changing Latin American Attitude: Prerequisite to Institutionalizing Democracy" en R. A. Pastor, ob. cit, pp. 96-103; y T.E. Skidmore (1989): "The Future of Democracy: An Analytical Summary”, en Pastor, ob. cit., pp. 133-138. 
coadyuvan en generar un mayor nivel de acercamiento entre los vértices del triángulo sociedad-partidosParlamento. Además, la premisa por parte del diputado de haber sido elegido porque el elector asumía el programa del partido y no por simpatía personal o por arrastre del líder del partido indica que se está ante partidos con una sólida y firme estructura capaz de superar vaivenes y liderazgos coyunturales.

De acuerdo a la percepción de los diputados latinoamericanos, los partidos latinoamericanos tienen un nivel medio de democracia interna (ver cuadro 5). Buena parte de los diputados entrevistados de Rep. Dominicana (63\%), El Salvador $(54 \%)$ y Costa Rica $(42 \%)$ perciben que el grado de democracia interna en sus partidos es muy alto o alto, contrastando con los bajos porcentajes de los diputados de Chile (17\%) y Colombia (20\%). Al evaluar las respuestas de los que opinan que el grado de democracia interna partidista es bajo o muy bajo se constata una gran homogeneidad al quedar situado el corchete de las respuestas para los diecisiete casos nacionales estudiados entre el 6\% de El Salvador y el 30\% de Colombia. Sería necesario realizar un análisis complementario de estos aspectos para contrastar estas opiniones, así como una utilización de distintos indicadores para poder comparar los grados de democracia interna. En todo caso, puede resultar suficientemente significativo que miembros relevantes de los mismos partidos, como son los diputados nacionales, afirmen que la democracia interna de sus partidos no es una característica relevante de los mismos.

En cuanto a la estructura partidista (cuadro 6), la inmensa mayoría de los diputados considera que su partido tiene una estructura continua, aunque hay diferencias significativas, puesto que bastantes diputados consideran que la estructura de su partido es únicamente electoral. De los primeros merecen destacarse los casos de Panamá, Venezuela, Chile y Uruguay en los que más del $90 \%$ de los entrevistados sitúa a los partidos como entes con estructura continua. Por el contrario, a la cabeza de los que sitúan a sus partidos como una estructura exclusivamente electoral destacan Colombia (55\%), Perú (51\%), Honduras $(40 \%)$ y El Salvador (39\%) lo que no deja de ser sorprendente en el primer caso, toda vez que los partidos más importantes en Colombia son partidos de muy larga trayectoria; no así en Perú, donde el partido que apoya al actual presidente, Alberto Fujimori, es uno de los ejemplos más claro de partido equivalente a plataforma electoral.

Por último, la otra variable relevante para analizar el grado de acercamiento entre la sociedad, los partidos y los parlamentos se refiere a la importancia que los diputados otorgan a su adscripción a un partido, como forma de conseguir su escaño (cuadro 7 y figura 4), en contraposición a otros factores decisivos para su elección, como la simpatía personal o la ausencia de alternativas de voto. Dentro del primer caso, se contemplan tres elementos pertenecientes al universo partidista y que se refieren a la identificación del elector con los postulados ideológicos como factor que interviene en su elección, el arrastre del líder del partido o al tipo de campaña desarrollado. En este sentido, la per- cepción de que han sido elegidos porque el elector asumía el programa del partido es la opción mayoritaria entre los diputados latinoamericanos, salvo en Colombia y Chile. La simpatía personal es un factor significativo para los diputados de Panamá y Colombia. El apoyo del partido en lo que se refiere al estilo de campaña o al arrastre del líder del partido son opciones relativamente relevantes para numerosos diputados de Uruguay, Costa Rica, Venezuela, Chile y Perú. En suma, parece que los factores esenciales que intervienen en la elección de un diputado se ubican dentro del espacio propio de los partidos. Por tanto, según estas percepciones, los partidos seguirían siendo piezas fundamentales en el desempeño de la función de ganar elecciones, siendo mucho más limitadas y críticas las funciones que realizan de representación de intereses sociales y en todo lo que supone su activación como canales de intermediación entre la sociedad y las instituciones políticas. Obviamente esta circunstancia se ve favorecida por cuanto que el sistema de listas cerradas y bloqueadas mayoritariamente imperante en los procesos electorales latinoamericanos confiere un gran poder a la maquinaria del partido.

\section{II.3. Institucionalización y Representación: ¿dos caras de una misma moneda?}

Si compararamos nuestros datos con los facilitados por Mainwaring y Scully (1995) ${ }^{21}$, comprobaríamos que existen diferencias interesantes. Estos autores establecen un patrón de institucionalización para los sistemas de partidos en América Latina, que va más allá de los dos criterios fijados por Sartori $(1976)^{22}$, que serían la volatilidad electoral ${ }^{23}$, los vínculos entre partidos, ciudadanos e intereses organizados ${ }^{24}$, estos ciudadanos e intereses organiza-

21. S. Mainwaring y T.R. Scully ((Eds.)(1995): Building Democratic Institutions. Party Systems in Latin America, Stanford Univ. Press, Stanford.

22. El número de partidos relevantes que compiten y el grado de polarización ideológica. Véase G. Sartori (1976): Parties and Party Systems: A Framework for Analysis, New York: Cambridge University Press. La propuesta de "racionalización" de Sartori incluye tres principios, a nuestro juicio, más relevantes: 1 ) los partidos no son facciones; 2 ) un partido es parte de un todo; y 3) los partidos son canales de expresión.

23. La volatilidad en las elecciones legislativas que analizan Mainwaring y Scully para el período 1970-1990, en la mayoría de los países latinoamericanos, muestra grandes diferencias, desde el punto más bajo de la escala donde se sitúa Colombia ( $8,5 \%)$, seguida de Uruguay $(9,1 \%)$, Argentina (12,7 \%), Chile $(15,8 \%)$, Venezuela $(17,7 \%)$ y Costa Rica $(18,2 \%)$. México se encuentra en una posición intermedia $(22,4 \%)$, Paraguay (25,8 \%), Ecuador (32,5\%), Bolivia (33,0\%); Brasil (40,9\%), y por último, Perú (54,4 \%) (Mainwaring y Scully (1995), ob. cit., pág. 8).

De ahí, establecen que los patrones de competición partidista son bastante estables en Uruguay y Colombia; moderadamente estables en Chile, Costa Rica, Venezuela y Argentina; bastante inestables en México, y extremadamente inestables en Paraguay, Bolivia, Brasil, Ecuador y Perú.

24. Con la excepción de Brasil y Ecuador, Mainwaring y Scully establecen, comparando los datos de las votaciones en elecciones presidenciales y legislativas, que los partidos tienen sólidos vínculos con la sociedad en Uruguay, Costa Rica, Chile, Venezuela, Argentina y Colombia (Mainwaring y Scully (1995), ob. cit., pág. 11).

Así mismo, los intereses organizados deberían tener mayores cone xiones con los partidos en los sistemas de partidos más institucionaliza dos. Los vínculos más estrechos en períodos democráticos se encontrarían en Venezuela, Chile, Costa Rica y Uruguay. En estos países, los partidos "encapsularían" las mayores organizaciones sociales. 
dos deben percibir que los partidos y las elecciones son los medios de determinar quién gobierna y los partidos y los procesos electorales deben gozar de legitimidad ${ }^{25}$, y por último, que las organizaciones partidistas, deben ser relativamente sólidas en aquellos países que tienen sistemas de partidos institucionalizados ${ }^{26}$.

La agregación de estas cuatro dimensiones permite a Mainwaring y Scully conformar una tabla con una ordenación del proceso de institucionalización de los sistemas de partidos en los distintos sistemas políticos de América Latina $^{27}$, donde Costa Rica, Chile, Uruguay, Venezuela y Colombia, y en menor grado, Argentina ${ }^{28}$, se situan en los primeros lugares del ranking, aunque por supuesto existirían diferencias de unos casos nacionales a otros. ¿Qué significa esta institucionalización de los sistemas de partidos?. Los autores señalan que "los partidos políticos más importantes se encuentran institucionalizados, y el porcentaje de votos que consiguen es razonablemente estable de unas elecciones a las siguientes. En términos de volatilidad electoral, los sistemas de partidos institucionalizados ocupan las seis posiciones bajas de la escala. Los partidos tienen al menos raíces moderadamente fuertes con la sociedad civil y unas identidades más moderadas. Son actores claves en torno a los que se estructura el proceso electoral y la elección de los gobernantes, y donde las organizaciones partidistas no son una simple expresión de los deseos políticos de unos líderes carismáticos" ${ }^{29}$.

En el caso de los países que ocupan los últimos lugares en esta clasificación (Bolivia, Ecuador, Brasil y Perú), cuentan con sistemas de partidos débilmente institucionalizados, a los que califican de "inchoate party systems" ${ }^{30}$. Estos sistemas de partidos se caracterizarían por débiles organizaciones partidistas, elevada volatilidad electoral, raíces débiles en la sociedad civil, y donde las personalidades individuales dominan los partidos y las campañas. Aún así, estos autores señalan que en los cuatro países los partidos tienen un perfil ideológico razonablemente claro a nivel de las élites. En el caso de México y Paraguay, nos encontraríamos con dos casos nacionales donde los partidos políticos no funcionan todavía en un sistema realmente competitivo, así son calificados como "sistemas de partido hegemónico en transición".

Sin embargo, aunque destacando la limitación de nuestros datos - dado que nuestra investigación aborda el tema partidista desde la perspectiva de la élite parlamentaria, eje central de nuestro trabajo-, sí resulta sorprendente en principio encontrarnos con que en buena parte de estos sistemas de partidos institucionalizados, los diputados perciben el progresivo alejamiento de los partidos frente a la sociedad y al ciudadano (el ejemplo más destacado sería el de Chile, que además se vería también perturbado por los propios problemas que han sufrido los partidos políticos, la conformación de una derecha relativamente reciente, después de la transición, los problemas entre el PS y el PPD, los problemas internos en el seno de la Democracia Cristiana para buscar un recambio al actual líder, etc). Quizás, y retomaríamos en cierto sentido, el debate de nuestra introducción, en efecto, los partidos políticos en
América Latina han logrado incardinarse de forma estable en los sistemas políticos, lo que es decir en el Estado, han monopolizado durante las transiciones políticas el acceso de los ciudadanos al sistema, pero una vez que este "viaje inicial e iniciático" parece haber concluido, la sensación es que los partidos no han fortalecido sus nexos con la sociedad. Cada vez resulta menos importante el apoyo prolongado de unas bases sociales a nivel partidista, cuya movilización excesiva puede resultar peligrosa para el sistema político, tampoco resulta excesivamente rentable a nivel electoral el intento de recobrar el apoyo de cierto electorado marginalizado por las nuevas condiciones económicas (recordemos que el último informe de la CEPAL señalaba en estos países el incremento del paro y del empleo encubierto, que llega a representar en algunos casos el $95 \%$ de la población económicamente activa).

Por supuesto, y en esto compartimos la premisa básica de Mainwaring y Scully ${ }^{31}$, que la institucionalización de un sistema de partidos es importante porque explica cómo

25. Aquí, Mainwaring y Scully ((1995), ob. cit., pág. 14) sólo ofrecen estimaciones dado que no disponen de encuestas: en Venezuela, Costa Rica, Chile, Uruguay y Colombia, los partidos se han mostrado cruciales a la hora de determinar quién gobierna; en Argentina, Brasil, Ecuador y Bolivia se encuentran en un proceso parecido de adecuación, y sólo en México, Paraguay y, después de 1992, en Perú, los partidos y elecciones parecen tener un papel más reducido.

26. Parece obvio, señalan estos autores, que las organizaciones partidistas en Venezuela, Costa Rica, Chile, Uruguay, México, y Paraguay, son las más fuertes y más institucionalizadas de América Latina: las élites políticas son leales a sus partidos, y la disciplina de partido durante la legislatura es razonablemente sólida; los partidos están bien organizados, y disfrutan de una presencia considerable tanto a nivel nacional como local. Colombia y Argentina se situarían a un nivel intermedio, y los últimos lugares los ocuparían las organizaciones partidistas en Bolivia, Brasil, Ecuador y Perú (Mainwaring y Scully, (1995), ob. cit., pág. 16).

27. Reproducimos los datos que figuran en dicha tabla (Mainwaring y Scully (1995), ob. cit., pág. 17):

Party System Institutionalization in Latin America

\begin{tabular}{lccccc}
\hline Country & Criter. 1 & Criter. 2 & Criter. 3 & Criter. 4 & Aggregate \\
\hline Costa Rica & 2.5 & 3.0 & 3.0 & 3.0 & 11.5 \\
Chile & 2.5 & 3.0 & 3.0 & 3.0 & 11.5 \\
Uruguay & 3.0 & 3.0 & 3.0 & 2.5 & 11.5 \\
Venezuela & 2.5 & 2.5 & 2.5 & 3.0 & 10.5 \\
Colombia & 3.0 & 3.0 & 2.5 & 2.0 & 10.5 \\
Argentina & 2.0 & 2.5 & 2.5 & 2.0 & 9.0 \\
Mexico & 1.5 & 2.5 & 1.5 & 3.0 & 8.5 \\
Paraguay & 1.0 & 2.5 & 1.0 & 3.0 & 7.5 \\
Bolivia & 1.0 & 1.0 & 2.0 & 1.0 & 5.0 \\
Ecuador & 1.0 & 1.0 & 2.0 & 1.0 & 5.0 \\
Brazil & 1.0 & 1.0 & 2.0 & 1.0 & 5.0 \\
Perú & 1.0 & 1.0 & 1.0 & 1.5 & 4.5 \\
\hline
\end{tabular}

(Donde, 3.0=alto; 2.5=medio-alto; $2.0=$ medio; $1.5=$ =medio-bajo; $1.0=$ bajo).

28. En el caso argentino, han sido frecuentes los análisis que han insistido en el hecho de que Argentina cuenta con partidos políticos fuertes pero que sin embargo no se institucionalizaron, es decir, no se correspondieron con un sistema de partidos fuerte (M. Cavarozzi (1989): "El esquema partidario argentino: partidos viejos, sistema débil”, en M. Cavarozzi y M.A. Garretón, (Coord.) (1989): Muerte y resurrección. Los partidos politicos en el Autoritarismo y las transiciones del Cono Sur, FLACSO, Santiago de Chile).

29. Mainwaring y Scully (1995), ob. cit., pág. 17

30. Mainwaring y Scully (1995), ob. cit., pág. 19

31. Mainwaring y Scully (1995), ob. cit, pp. 21-22. 
funciona la democracia en ese sistema político, y por qué explica también la consolidación de esa misma democracia (aunque los autores ni usan ni abusan de este concepto, al menos así parece deducirse de lo que sostienen: "nuestro énfasis aquí es sobre las consecuencias de la institucionalización de un sistema de partidos para la democracia. Se da también el caso de que una democracia estable refuerza la institucionalización de un sistema de partidos") ${ }^{32}$. Pero no deja de ser preocupante que el proceso de institucionalización venga a entronizar a los partidos políticos dentro de un sistema político, y relegue a un segundo plano aspectos sustantivos para "la calidad de la democracia" como puede ser la representatividad ${ }^{33}$.

En este sentido, y si repasaramos las condiciones que consideran Cavarozzi y Garretón (1989) para poder hablar de consolidación de un sistema de partidos, veríamos como los partidos políticos latinoamericanos dejan todavía mucho que desear en este ámbito: 1) el sistema de partidos debe ser inclusivo (es decir, debe incorporar a todos los sectores sociales e ideológicos); 2) debe ser representativo (es decir, los partidos deben contar con un arraigo en la sociedad y la sociedad debe confiar en éstos); 3) el canal partidista no debe ser exclusivo en la expresión de los intereses y demandas sociales (lo que plantea toda la cuestión de la descentralización y desconcentración del poder y de las instancias de participación social, de modo que los clivajes sociales no sean pura expresión de los conflictos partidistas); 4) la concertación o alianza mayoritaria entre las fuerzas políticas que combinan adhesión democrática con cambio social democratizador y el abandono de sus tendencias de mutua absorción o exclusión; y por último, debe existir un principio ético de adhesión democrática; una democratización social, aunque también un principio instrumental de concertación y un principio de flexibilidad y de subordinación de la "razón de partido" a la "razón colectiva o nacional" ${ }^{34}$.

\section{CONCLUSIONES}

Los partidos políticos han cumplido tradicionalmente determinadas funciones, entre las que cabría mencionar, como señalan Rokkan y Lipset — "la doble fascinación": la de cristalizar y explicitar los intereses en lucha en la estructura social existente y la de obligar a individuos y ciudadanos a aliarse más allá de los clivajes estructurales ${ }^{35}$. Pero antes de atreverse a afirmar un declive de los partidos políticos, deberíamos partir del supuesto de que no todos los sistemas políticos tienen idénticas necesidades funcionales o idéntica intensidad. Como señala Von Beyme ${ }^{36}$, "no hay signos que indiquen que estas tendencias vayan a hacer obsoleto el Estado de partidos", no serían "sino un exponente del cambio funcional del papel de los partidos en las modernas democracias".

Por otro lado, deberíamos también destacar que "el tiempo político” (en nuestro caso, las transiciones democráticas que experimentaron buena parte de los países latinoamericanos desde finales de la década de los setenta hasta 1989, año en que se produce la recuperación demo- crática chilena) en el que los partidos políticos latinoamericanos asumen determinadas tareas y funciones es distinto del ejemplo europeo. Es decir, los partidos políticos fueron los catalizadores de la mayor parte de los derechos, deseos y esperanzas de las sociedades latinoamericanas, pero una vez recuperada la democracia en un contexto de crisis económica, acaba produciéndose una frustración entre el volumen de pretensiones y la capacidad de dirección, que culmina "en una pérdida de confianza que se debe notar en la relación entre las organizaciones de los partidos, por un lado, y sus electores y miembros, por otro" ${ }^{37}$.

Sin embargo, el cierto - de certeza y cantidaddesencanto postdemocrático que ha aparecido en los países latinoamericanos, no ha significado que la democracia se haya visto seriamente afectada (en el sentido de una involución autoritaria); convendría en este sentido retomar la distinción de Easton entre las dos clases de apoyo, el difuso y el específico ${ }^{38}$. Así, "un sistema político democrático requiere una reserva de apoyo difuso independiente de los resultados políticos inmediatos (apoyo específico) si tiene que manejar períodos de desafección e insatisfacción públicas" ${ }^{39}$.

32. Mainwaring y Scully (1995), ob. cit., pág. 481.

33. Entendida como representación de intereses que no son los estrictamente partidistas. Véase P.C. Schmitter (1993): “La consolidación de la democracia y representación de grupos sociales” en Revista Mexicana de Sociologia, n.3. En este sentido, resulta irónico, se lamenta Schmitter, que precisamente cuando el corporatismo parece estar desapareciendo (o agoniza) en las antiguas democracias, esté siendo revivido en las de nuevo cuño, y que de ser un "consumidor" de legitimidad bien establecido en las dependencias estatales, se haya transformado en "productor" para los recientes regímenes democráticos (Schmitter (1993), art. cit., pág. 16).

34. M. Cavarozzi y M.A. Garretón (Coord.) (1989), ob. cit., pp. 22-23.

35. S. M. Lipset y S. Rokkan (1967): Party Systems and Voter Alignments, Free Press, New York.

36. K. Von Beyme (1986): Los partidos politicos en las democracias occidentales, Centro de Investigaciones Sociológicas, Madrid.

37. Como abunda Offe: "Está originada por tener los partidos que frustar precisamente las expectativas que ellos mismos han generado, y que han sido la base desde la que han conseguido una mayoría en el gobierno". Y añade: "Las esperanzas que crea cada plataforma electoral quedan sin cumplir, mientras que las medidas 'duras' (por ejemplo, en la política de salarios, fiscal y de justicia) se tienen que tomar, aunque el partido haya renunciado antes expresamente a recurrir a ellas". C. Offe, ob. cit., pág. 31 .

38. En primera instancia, David Easton distingue el apoyo entre tres niveles de los objetos políticos: a) las autoridades políticas (el descontento respecto a éstas normalmente tiene consecuencias políticas limitadas); b) el régimen (un cambio en el apoyo al régimen puede provocar un cambio básico en las estructuras constitucionales o en los procedimientos de gobierno, y c) la comunidad política (el debilitamiento de los vínculos con la comunidad política en un sistema democrático puede conducir a la revolución, la guerra civil o la pérdida de la democracia). Como puede verse, "no todas las expresiones de orientaciones desfavorables tienen el mismo grado de gravitación para un sistema político. Algunas pueden ser consistentes con su mantenimiento, otras pueden conducir a un cambio fundamental"(1975:437). En segundo término, Easton distingue dos clases de apoyo: el difuso (un apoyo al sistema político que trasciende el comportamiento actual del gobierno) y el específico (respecto a las acciones del gobierno o de las élites políticas). Véase D. Easton (1965): A System of Analysis of Political Life, Wiley, New York, y (1975): "A reassessment of the concept of political support", British Journal of Political Science, 5:435-57.

39. R. Dalton, ob. cit, pág. 228. 
El proceso de autonomización de los partidos frente a la sociedad, por un lado, y por otro, el fortalecimiento de los vínculos que ya mantenían con el Estado, ha hecho que "la relevancia de los vínculos que se basaban en la confian$z a$, responsabilidad, y sobre todo, representación, tiendan a erosionarse, tanto dentro como fuera de los partidos" ${ }^{40}$. En este sentido, consideramos que la percepción que tiene la élite parlamentaria en la mayoría de estos países resulta de fundamental importancia para recobrar la confianza de la sociedad civil, y en mucha mayor medida, para garantizar los procesos de consolidación dentro de unos cauces democráticos.

40. P. Mair, ob. cit., pp. 18-19.

\section{A N E X O}

CUADRO 1

RELACIÓN PARTIDOS POLÍTICOS Y SOCIEDAD (\%)

\begin{tabular}{|c|c|c|c|c|c|c|c|c|c|c|c|c|c|}
\hline & 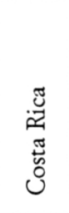 & 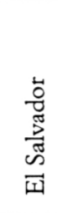 & 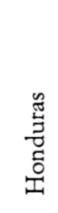 & 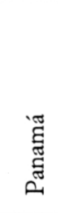 & 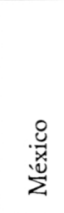 & 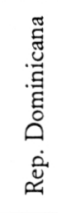 & 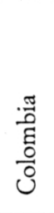 & 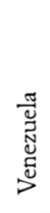 & 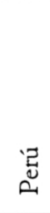 & 劳 & 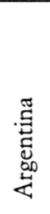 & $\begin{array}{l}\text { 㔄 } \\
\text { 总 } \\
\text { 号 }\end{array}$ & 㻤 \\
\hline Fuertes vínculos & 40 & - & - & 43 & 13 & 42 & 5 & 1 & 3 & 7 & 3 & 14 & 8 \\
\hline Progresivo alejamiento & 54 & - & - & 35 & 61 & 52 & 68 & 73 & 34 & 84 & 70 & 78 & 44 \\
\hline Gran distancia & 2 & - & - & 6 & 15 & 5 & 25 & 26 & 60 & 7 & 27 & 8 & 48 \\
\hline $\mathrm{N}=$ & 52 & & & 54 & 121 & 62 & 63 & 69 & 87 & 94 & 30 & 73 & 61 \\
\hline
\end{tabular}

CUADRO 2

NIVEL DE MILITANCIA EN SU PAÍS (\%)

\begin{tabular}{|c|c|c|c|c|c|c|c|c|c|c|c|c|c|}
\hline & 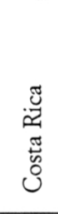 & 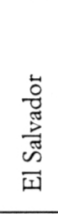 & 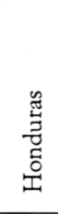 & 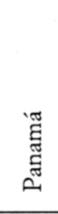 & $\begin{array}{l}\stackrel{8}{*} \\
\text { : }\end{array}$ & 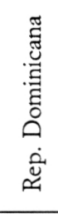 & 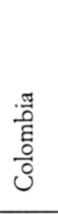 & 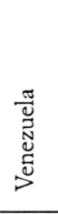 & 营 & 를 & 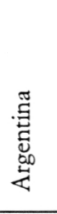 & $\begin{array}{l}\text { 总 } \\
\text { d. } \\
\text { 号 }\end{array}$ & 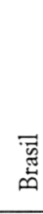 \\
\hline Muy alto & 10 & 2 & 18 & 7 & 2 & 16 & & 6 & & & & 1 & 5 \\
\hline Alto & 21 & 28 & 54 & 13 & 7 & 52 & 8 & 14 & 3 & 4 & 20 & 8 & 2 \\
\hline Medio & 46 & 50 & 27 & 53 & 27 & 26 & 49 & 29 & 9 & 23 & 33 & 36 & 28 \\
\hline Bajo & 17 & 17 & - & 16 & 51 & 5 & 24 & 35 & 31 & 66 & 37 & 45 & 39 \\
\hline Muy bajo & 6 &. & 1 & 11 & 11 & 2 & 19 & 13 & 56 & 6 & 10 & 10 & 26 \\
\hline $\mathrm{N}=$ & 52 & 46 & 67 & 55 & 123 & 62 & 63 & 69 & 87 & 94 & 30 & 73 & 61 \\
\hline
\end{tabular}

CUADRO 3

PARTICIPACIÓN POPULAR EN LOS PARTIDOS POLÍTICOS (\%)

\begin{tabular}{|c|c|c|c|c|c|c|c|c|c|c|c|c|c|}
\hline & 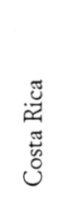 & 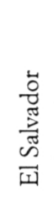 & 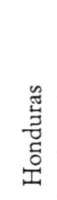 & 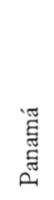 & 总 & 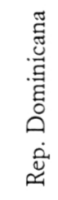 & 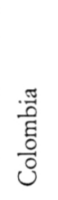 & 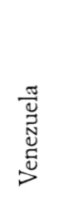 & 䓌 & 胥 & 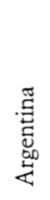 & 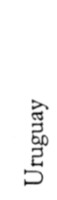 & 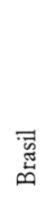 \\
\hline Escasa y marginal & 6 & 11 & 4 & 32 & 12 & 7 & 28 & 23 & 22 & 37 & 30 & 16 & 21 \\
\hline Sólo en elecciones & 71 & 65 & 39 & 52 & 67 & 61 & 67 & 64 & 65 & 60 & 57 & 66 & 75 \\
\hline Intensa y constante & 21 & 22 & 57 & 15 & 19 & 32 & 2 & 13 & 8 & 3 & 13 & 5 & 3 \\
\hline$N=$ & 52 & 46 & 67 & 54 & 122 & 62 & 61 & 69 & 87 & 94 & 30 & 73 & 61 \\
\hline
\end{tabular}


CUADRO 4

IMPORTANCIA DE LA IDEOLOGIAA EN LOS PARTIDOS (\%)

\begin{tabular}{|c|c|c|c|c|c|c|c|c|c|c|c|c|c|}
\hline & 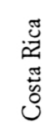 & 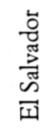 & 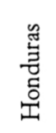 & 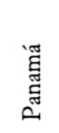 & 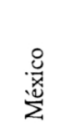 & 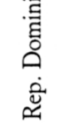 & $\begin{array}{l}\text { : } \\
\text { है } \\
\text { 응 }\end{array}$ & 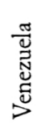 & 芯 & 苞 & 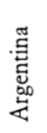 & $\begin{array}{l}\text { 勇 } \\
\text { 品 } \\
\text { : }\end{array}$ & 䞤 \\
\hline $\begin{array}{l}\text { No hay diferencia } \\
\text { ideológica }\end{array}$ & 67 & 63 & 81 & 57 & 34 & 53 & 92 & 28 & - & 56 & 48 & 37 & 41 \\
\hline $\begin{array}{l}\text { La ideología de la izquierda } \\
\text { es más sólida }\end{array}$ & 4 & 11 & 4 & 7 & 16 & 14 & & 9 & - & 4 & 24 & 15 & 41 \\
\hline $\begin{array}{l}\text { La ideología } \\
\text { es irrelevante }\end{array}$ & 10 & 6 & 5 & 6 & 1 & 17 & 5 & 19 & - & 4 & 7 & 8 & 3 \\
\hline $\begin{array}{l}\text { La polarización ideológica } \\
\text { es extrema }\end{array}$ & 6 & 13 & 9 & 11 & 25 & 17 & 2 & 44 & - & 4 & 3 & 7 & 7 \\
\hline $\mathrm{N}=$ & 52 & 46 & 67 & 54 & 88 & 36 & 62 & 68 & & 90 & 29 & 72 & 61 \\
\hline
\end{tabular}

CUADRO 5

GRADO DE DEMOCRACIA INTERNA (\%)

\begin{tabular}{|c|c|c|c|c|c|c|c|c|c|c|c|c|c|}
\hline & 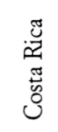 & 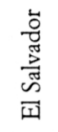 & 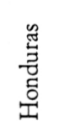 & 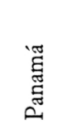 & 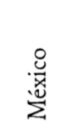 & 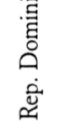 & 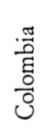 & 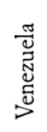 & ב⿱山口心 & : & 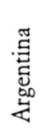 & $\begin{array}{l}\text { 祭 } \\
\text { 岂 } \\
\text { 号 }\end{array}$ & 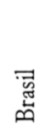 \\
\hline Muy alto & 2 & 6 & 6 & 4 & 15 & 19 & 2 & 16 & 2 & 2 & 3 & 7 & 5 \\
\hline Alto & 40 & 46 & 28 & 22 & 29 & 43 & 17 & 26 & 31 & 15 & 20 & 22 & 25 \\
\hline Medio & 50 & 39 & 46 & 51 & 37 & 32 & 49 & 45 & 40 & 57 & 53 & 49 & 47 \\
\hline Bajo & 8 & 4 & 15 & 18 & 14 & 2 & 16 & 9 & 16 & 23 & 17 & 16 & 18 \\
\hline Muy bajo & - & 2 & 4 & 5 & 4 & 3 & 14 & 4 & 6 & - & 7 & 5 & 3 \\
\hline $\mathrm{N}=$ & 52 & 46 & 67 & 55 & 123 & 62 & 63 & 69 & 87 & 94 & 30 & 73 & 61 \\
\hline
\end{tabular}

CUADRO 6

ESTRUCTURA INTERNA DEL PARTIDO (\%)

\begin{tabular}{|c|c|c|c|c|c|c|c|c|c|c|c|c|c|}
\hline & 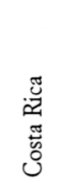 & 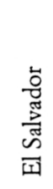 & 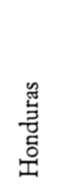 & 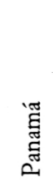 & 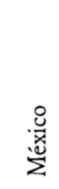 & 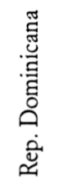 & $\begin{array}{l}\text {. } \\
\frac{0}{0} \\
\frac{0}{0} \\
0\end{array}$ & 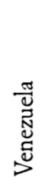 & ב & 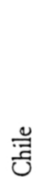 & 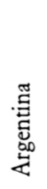 & 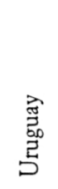 & 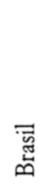 \\
\hline Contínua & 79 & 59 & 60 & 94 & 84 & 85 & 45 & 91 & 46 & 95 & 83 & 93 & 77 \\
\hline Sólo electoral & 19 & 39 & 40 & 4 & 16 & 15 & 55 & 9 & 48 & 3 & 17 & 6 & 20 \\
\hline $\mathrm{N}=$ & 52 & 46 & 67 & 54 & 122 & 62 & 62 & 68 & 87 & 94 & 30 & 73 & 61 \\
\hline
\end{tabular}

CUADRO 7

RAZÓN DE SU ELECCIÓN (\%)

\begin{tabular}{|c|c|c|c|c|c|c|c|c|c|c|c|c|c|}
\hline & 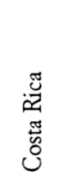 & 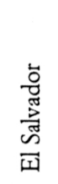 & 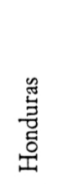 & 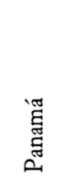 & 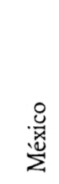 & 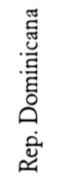 & 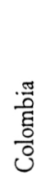 & 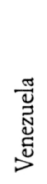 & 芯 & 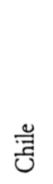 & $\begin{array}{l}\text { 莺 } \\
\text { 总 } \\
\text { 足 }\end{array}$ & 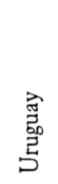 & 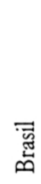 \\
\hline Asumir el programa & 35 & 55 & 37 & 45 & 58 & 40 & 15 & 40 & 29 & 21 & 50 & 32 & 43 \\
\hline Simpatía personal & 2 & 7 & 24 & 37 & 4 & 24 & 33 & 13 & 23 & 9 & 3 & 10 & 21 \\
\hline Ausencia de alternativas & 6 & 9 & 1 & - & 5 & 5 & 8 & 12 & 5 & 2 & 10 & 1 & 2 \\
\hline Tipo de campaña electoral & 20 & 2 & 10 & 14 & 11 & 8 & 18 & 7 & 10 & 28 & 3 & 8 & 15 \\
\hline Tradición familiar del votante & 8 & 12 & 15 & - & 3 & 8 & 2 & 6 & 1 & 7 & - & 1 & 4 \\
\hline Arrastre del líder del partido & 18 & 16 & 12 & 4 & 11 & 11 & 10 & 25 & 22 & 2 & 20 & 42 & - \\
\hline Otras & 12 & - & - & - & 7 & 3 & 13 & - & 10 & 31 & 14 & 3 & 15 \\
\hline $\mathrm{N}=$ & 51 & 44 & 67 & 51 & 120 & 62 & 60 & 67 & 87 & 93 & 30 & 72 & 53 \\
\hline
\end{tabular}




\section{GRÁFICO 1}

\section{DIFERENCIAS IDEOLÓGICAS}

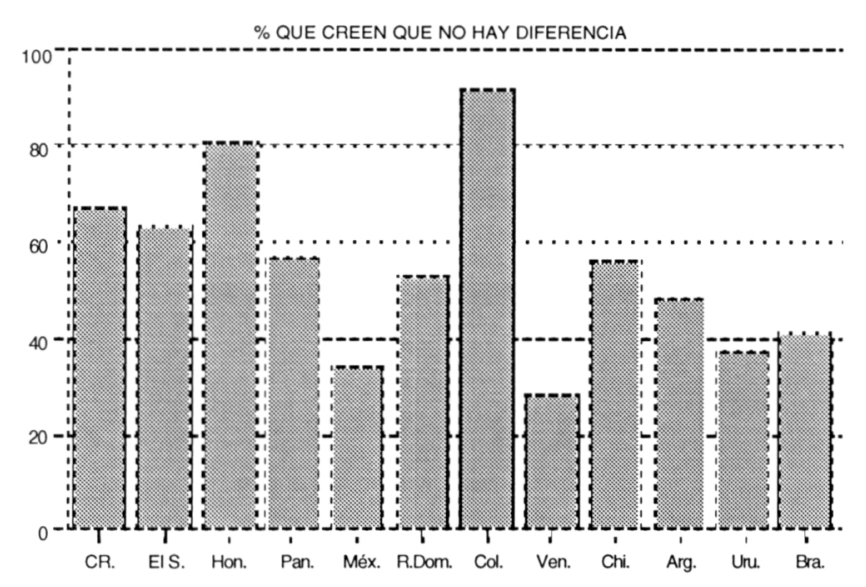

GRÁFICO 2

RAZÓN DE LA ELECCIÓN

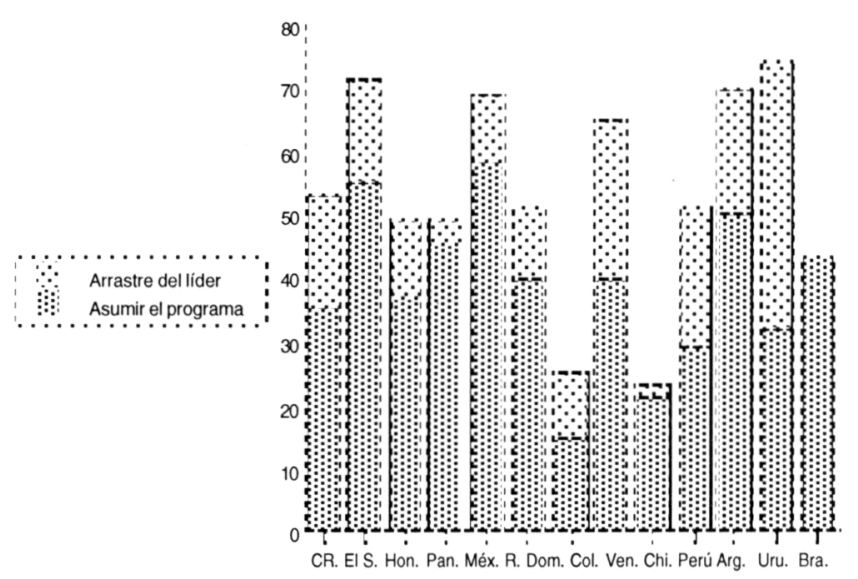

\section{RESUMEN}

En América Latina, parece haberse consolidado la vinculación de los partidos en el Estado y su consiguiente fortalecimiento, pero por otro, los partidos parecen haberse desvinculado de la sociedad, y en ese sentido, no están cumpliendo con su función de representación de los distintos intereses sociales. Así mismo, del análisis de las encuestas a los diputalos latinoamericanos, parece destacar la idea de que se está generando un modelo de partido claramente definible como institución decisional más que como institución representativa.

\section{ABSTRACT}

In Latin America, the linkage between the parties and the state has been consolidated, and this fact has implied the strengthening of these ones, but it has also meant a cut off from the civil society and a weakening of the representative function. Therefore, from the research of parliamentary elite, it looks clear that there is a new model of political party, less representative and with stronger ties with the state and government. 